by W.S. Fyfe

\title{
Soil and global change
}

\begin{abstract}
Increasing soil erosion is one of the greatest problems threatening the security of all species on the planet. We now have the tools to describe soil adequately in terms of its stability and potential for supporting sustained biologic productivity. We need new soil maps that focus on the carbon cycle and on the production of food and fiber.
\end{abstract}

Soil erosion can be controlled by using presently known simple technology. Humankind must recognize not only the limitations of all parts of our life support systems but also must acknowledge the limits on a population that can be provided a relatively high standard of living.

\section{Introduction}

The support systems for photosynthesis and carbon fixation in the Earth's environment involve the interactions of Sun, air. water, and soil. Today, we are changing dramatically our air $\left(\mathrm{CO}_{2}, \mathrm{CH}_{4}, \mathrm{CO}\right.$, $\mathrm{O}_{3}$, halogen acid. sulfuric acid, and nitric acid, for example). We are changing our rain and water, and we are changing our soil by a host of xenobiotic chemical additives, acid rain, and erosion. Additional subtle changes must result from the increasing atmospheric $\mathrm{CO}_{2}$. such as global warming and changes in the distribution of precipitation. If our soils are changing. the interactions of terrestrial life with the atmosphere must also change, and such changes must be built into climate models, an ability not possible at present.

At a meeting of "Planete Terre" in Paris. France, in June 1989. Lester Brown (see Brown, 1988) of the Worldwatch Institute emphasized that the first clear signals of global stress are showing in world food production. In Africa, the food available for each person has declined since the 1960s, and Latin America is now moving into the same situation. In 1988. for the first time in decades, grain production in the USA went into a 5 percent deficit, leaving no surplus in the country that traditionally has been the major grain reserve of the world. Despite the advances in agricultural technology, the supply of food becomes increasingly precarious. What are the causes? Climate fluctuation must play a part, but Brown (see Brown and Wolf, 1984) considers soil deterioration to be a primary cause of this "quiet crisis." Malnutrition and impure water are the major factors behind the huge child mortality rate of our world (about 40,000 children between the ages of 1 and 5 die daily).

Chaos theory. concerning the nature of nonlinear phenomena, indicates that when a well-behaved system is pushed beyond its limits, its future behavior becomes unpredictable. Along these lines, Worldwatch has drawn attention to a new class of people in our world called environmental refugees (Jacobsen. 1988, p. 11): "Mass migrations have become the enduring symbol of hunger." The situation is shown dramatically in parts of Africa and Bangladesh. and it can only get worse as we add 90 million more people to the Earth each year. A shortage of food and environmental deterioration are the precursors to Aldous Huxley's "frenzies of collective violence."

\section{What is soil?}

Soil is formed by the reactions of rock to air and water. Soil science is perhaps one of the most underdeveloped subjects of modern earth science. Although science requires the exact description of a system, necessary descriptions of soil on the microscale have not been possible previously, except in rare cases. Modern tools are required for these descriptions: geochemical analysis, structure analysis (for example, high-resolution electron microscopy), and, in particular, surface analysis and particulate analysis. These tools were not available for normal descriptive procedures until recently.

Soil consists of the following components. (1) Debris from the parent rock sets the stage, in large part, for the future chemistry. mineralogy, and biology of the soil. Air-borne dust may also be a significant component. (2) New minerals and amorphous materials form by weathering; these minerals are normally hydrated and frequently oxidized. A multitude of fine-grained particulate material is present as well. (3) Soil is the home for a host of micro-organisms. macro-organisms, and their debris, which are involved in key processes like nitrogen fixation, carbon fixation, and mineralization. (4) Soil provides the physical support system for the roots of plants. which are often finely adapted to local conditions. (5) Soil contains gas and liquid phases that are present in its pore spaces and as surface films on inorganic and biological materials. And (6) soil physics (thickness, porosity. permeability, rigidity, viscosity, strength, cohesion. compressibility. albedo) reflects all the above.

Soil is a dynamic system. Its biology varies with seasonal changes. Its liquid and gas phases vary on many time scales. Wetting and drying are reflected in transient solution and precipitation processes, mostly on surfaces of and in thin films of fine-grained materials. The physics of soil is dynamic.

Soil is a very complex system. It is dynamic on all microscales as it becomes wet or dry or warm or cold, and the biology changes in response to all changes in the physics and chemistry. The in-place interactions of all the pieces, living and dead, make this a system that is most difficult to describe.

\section{Toward a functional description of soil}

Although soil is complex. one overwhelming property or quality is significant for the biosphere (and humankind). This property or quality is based on the question: "Given a certain climate (temperature, rainfall, light, wind speed), what is the capacity of a soil to support photosynthetic organisms, to support carbon fixation, to support the production of food and fiber on a truly sustainable basis?" This same quality will determine the soil and plant modulation of the atmosphere by means of reactions of the soil with oxygen, carbon dioxide. and moisture, for example.

For humankind and for our economists, there are other key questions: "Is the soil changing? How is it changing? How rapidly? Is it becoming more--or less-productive?" 


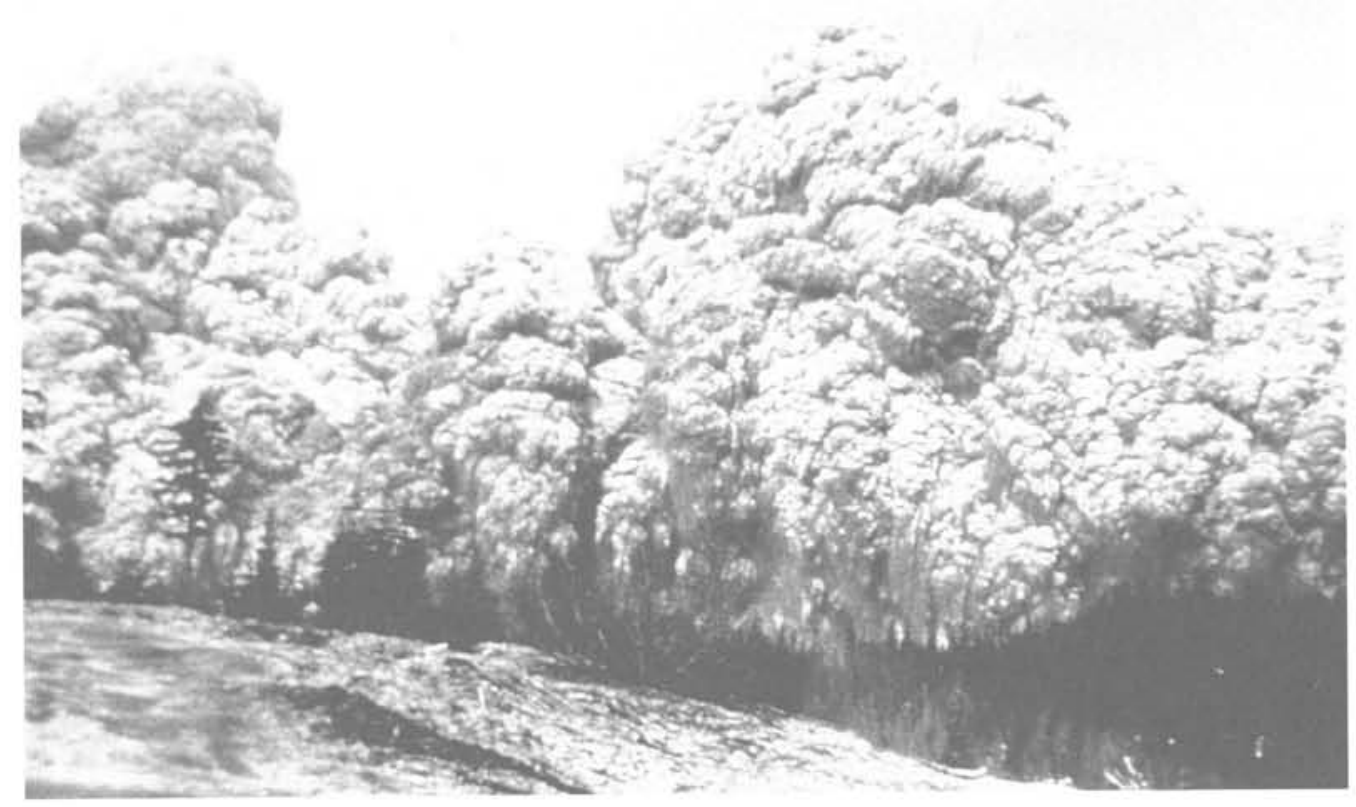

Figure 1.-New natural fertilizer: the dust cloud from Mount St. Helens, Washington, USA, in 1980.

\section{Erosion and soil thickness}

Today, the most dramatic changes occurring on a global scale are related to soil thickness. Erosion is the primary cause of change, but there are other causes of change, such as irrigation and salting, nutrient reduction because of overcropping, compaction and man-induced anaerobic conditions. Therefore, the relation between soil thickness and food and fiber productivity can be highly nonlinear.

The introduction of many herbicides, pesticides, new plant species, and industrial pollutants like lead surely must change the total biologic-geologic interactions. The new methods that appeared to be so successful over past decades are now showing massive fatigue, even failure. And many are worried about the new genetic engineering, the move to monocultures, and their almost-certain instability and vulnerability to fluctuations within the biosphere and the lithosphere.

\section{How do we estimate the local and regional health of soil?}

I would like to suggest that there are simple ways to obtain a useful estimate of the health of soils on a local and regional basis. All organisms from bacteria to trees require a wide range of macronutrients and micronutrients. Table 1 shows the levels of three key macronutrients in four great rivers of the world. Most of the water in these rivers passes through surface soil and rock. The levels of the three macronutrients and the total dissolved inorganic material (TDS) speak eloquently about the state of the soils. The Mississippi and Ganges river systems pass through younger soils that are loaded with rock-forming minerals. The Amazon and Negro systems flow through old laterite terranes. Their water indicates a low capacity to

Table 1.-Nutrients in major rivers

[Taken from Berner and Berner, 1987. L., lower. Units are given in parts per million]

\begin{tabular}{lcccc}
\hline River & $\begin{array}{c}\text { Calcium, } \\
\text { dissolved }\end{array}$ & $\begin{array}{c}\text { Magnesium, } \\
\text { dissolved }\end{array}$ & $\begin{array}{c}\text { Potassium, } \\
\text { dissolved }\end{array}$ & $\begin{array}{c}\text { Total } \\
\text { dissolved } \\
\text { solids }\end{array}$ \\
\hline Mississippi & 39 & 10.7 & 2.8 & 265 \\
L. Amazon & 5.2 & 1.0 & .8 & 38 \\
L. Negro & .2 & .1 & .3 & 6 \\
Ganges & 24.5 & 5.0 & 3.1 & 167 \\
\hline
\end{tabular}

support intense bioproductivity, probably the reason this region has not been overpopulated by the human species historically.

If we think of great fertile regions of the world, including Hawaii, southern Ontario, and the Nile Valley, all of these contain young soils and mineral debris. Plate boundaries are fertile, volcanic terranes are fertile, and regions that have been covered by sediments from diverse source rocks as a result of river, ice, or wind erosion are fertile. In contrast, the global agricultural-disaster regions have not had a sediment shock or an igneous mountain-building shock for millions of years (fig. 1). The macronutrients and micronutrients in these regions have passed now to the oceans. In fact, in some of these regions, the main input today may be from the air-borne particulates in dust and rain.

\section{Is soil a nonrenewable resource?}

According to the Worldwatch Institute, topsoil is being lost at a global rate of 0.7 percent per year, a rate that must be accelerating. If this is true, we are heading for a food catastrophe! How long does it take to form a 10 -cm-thick layer of fertile soil? (Note that I define fertile by the capacity of soil to produce food and fiber.) The answer to this question is found in nature itself. In a place like Hawaii, we can watch well-dated volcanic flows evolve into a cattle ranch or a forest (fig. 2). In northern Canada where clean rock was exposed after the ice retreated 10,000 years ago, there is often no soil. A range of $1,000-10,000$ years seems to be needed to produce a farmland from hard rocks. For us, this is a nonrenewable resource!

Conversely, rocks can be formed as a result of the erosion of soil (for example, deltaic rocks), and the formation of soil from these rocks may be much shorter. What takes time to turn these rocks into fertile soil is the creation of porosity and other physical properties that will allow the development of diverse biological support systems and that will create water-holding systems. How fast these processes occur will depend critically on the history of sediment compaction.

\section{The laws of conservation}

For sustainable carbon fixation, that is, agriculture, simple laws must apply. (1) The rate of soil loss must not exceed the rate of soil for 


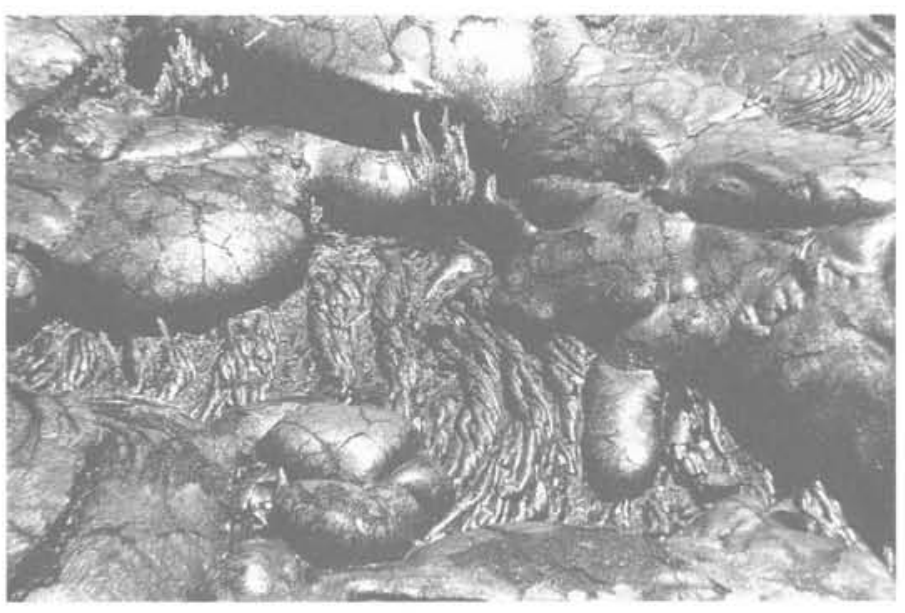

Figure 2.-A recent lava flow on the island of Hawaii, USA. The first plants are finding a home.

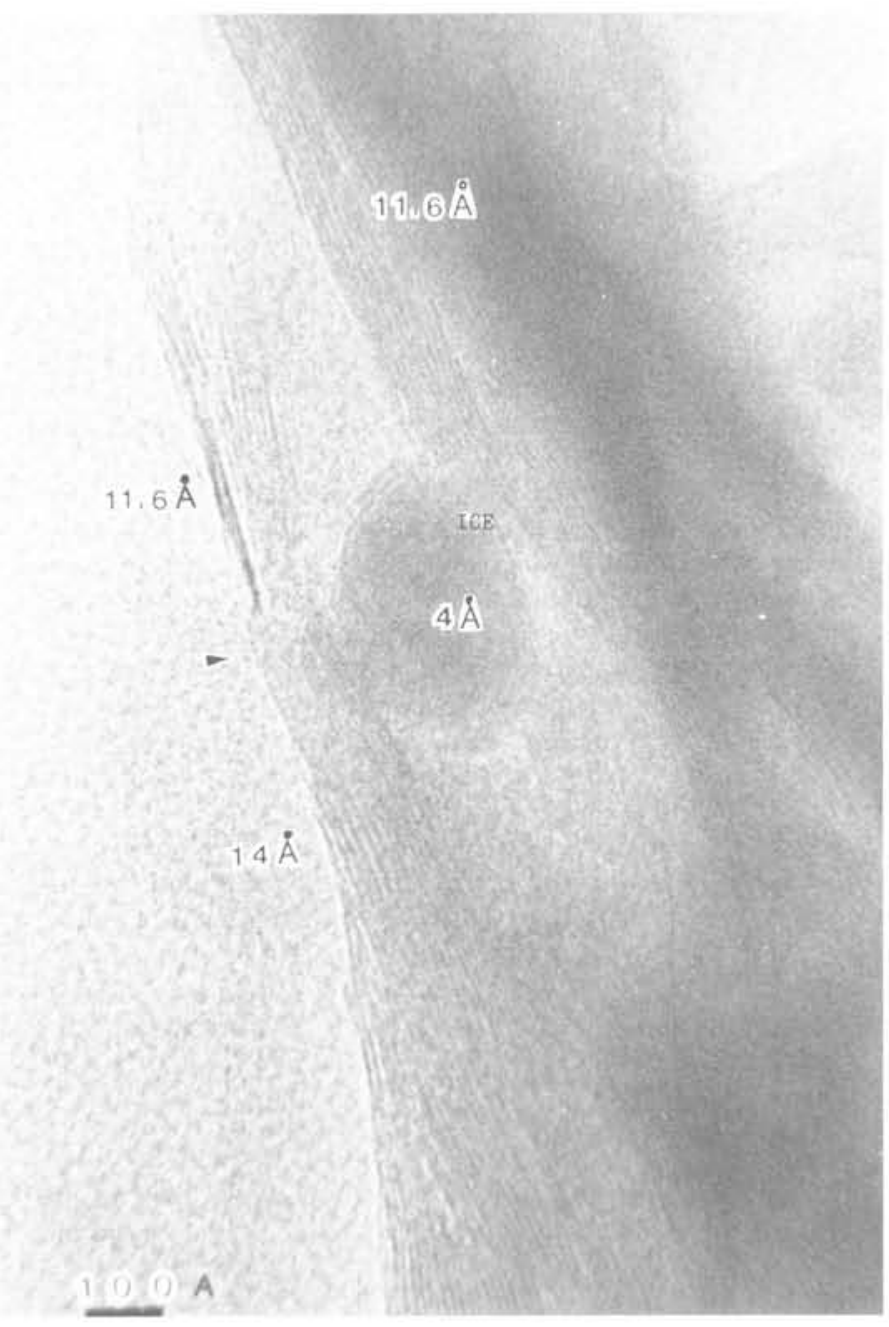

Figure 3.-Ice forming by the freezing of water in a swelling clay. Note the $100 \AA$ particles formed by disruption of the structure. mation. (2) The nutrients taken out by crops must be balanced by input for the entire spectrum of essential elements. And (3) the ability of soil to hold water must not be diminished because of agricultural practices. How often do we have the data to quantify such laws for large or small regions?

\section{Fine minerals in soil}

Soils obviously need a major component of very fine-grained material ranging from biologic debris to newly formed mineral precipitates. These materials have huge surface areas that will play a major role in plant-root interactions and buffer processes. They will be the best ion exchangers for the nutrient bank. They will hold moisture films. They will be the key buffers for acid precipitation or toxicmetal addition, all forms of shock. However, because they are often in the size range of $100-1,000 \AA$, they will be very sensitive to loss by wind and water erosion, raindrop-impact processes, and the like, as well as sensitive to agricultural practices.

These fine-grained materials must be vital to the control of the response times of living organisms. In some experiments performed at our university, we noticed that when conventional superphosphate was added to synthetic soils dominated by minerals like quartz, corn seeds could not germinate. There were no buffers to chemical shock!

Some examples of fine-grained materials that are formed by leaching and by bacteria are shown in figures 3,4 , and 5 . In figure 3. we show a picture from Tazaki and others (1987) of aerosol-sized particles formed by the freezing of wet swelling clays. Do such size-

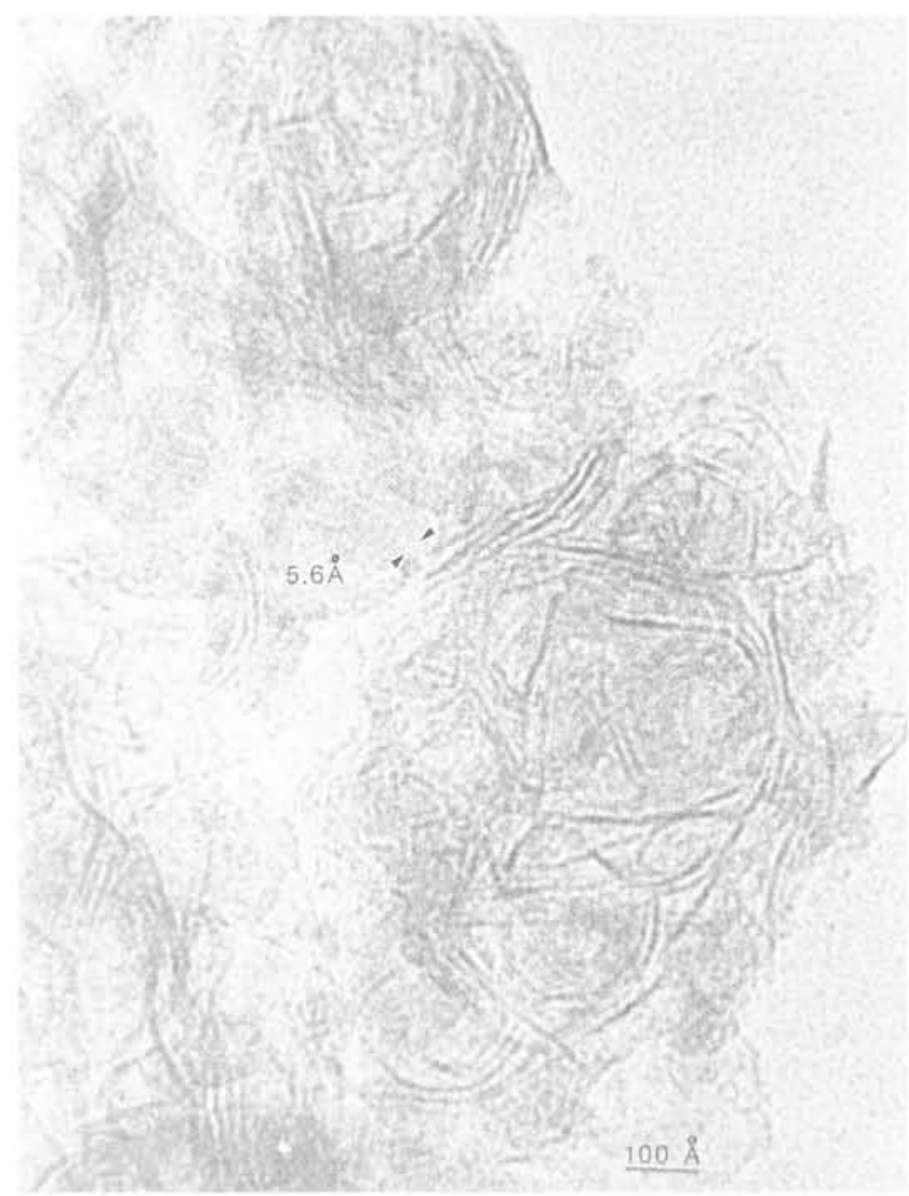

Figure 4. - Fine aluminum silicate fibers (with iron) formed by the leaching of potassium feldspar. 
reduction processes account in part for the susceptibility of highlatitude soils to wind erosion because they are subjected to thousands of freeze-thaw events?

\section{Quality control of additives to soil}

One hundred years ago, when world population was about 1 billion, the main agricultural additives were waste organic materials. Then came the age of mineral fertilizers and, particularly, phosphate fertilizers. Most phosphates are derived from marine deposits, and in the marine environment, phosphate minerals sequester large concentrations of elements like cadmium, uranium, and lead. The intensive use of phosphate fertilizers can lead to a massive buildup of elements like cadmium, a phenomenon of growing concern in many regions of intensive agriculture. Because a polluted soil is difficult to repair, the emphasis clearly must be placed on initial quality control. This type of control is needed urgently whenever we use any natural materials on a large scale. Quality control of coal is perhaps one of our most urgent problems, but other examples abound.

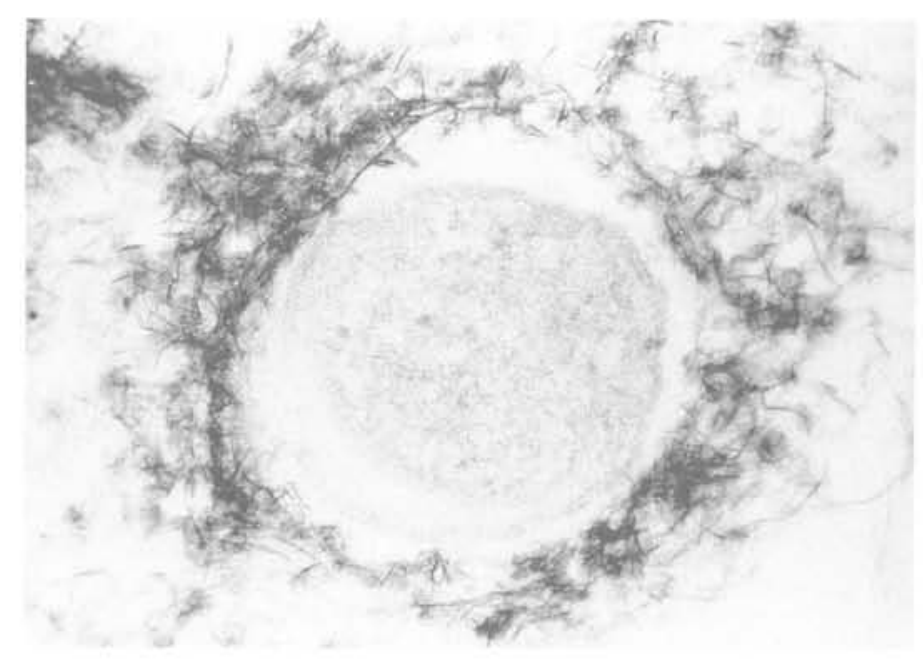

Figure 5.-Formation of an iron-rich clay induced on the cell wall of a bacteria found in a lake sediment (magnification $\times 100,000$ ).

\section{Erosion and potential catastrophe}

As mentioned above, the Worldwatch Institute has reported that global loss of topsoil is running presently at 0.7 percent per year. Although this figure may be challenged, it is cause for alarm even if it is close. Further, the consequences of topsoil loss go way beyond the problems of the food supply of the world. Today, carbon dioxide in the atmosphere is rising faster than ever. If a soil is failing, its carbon dioxide fixation processes will decline as well, and this coupling of problems has the potential to accelerate greenhouse warming.

As man invades the marginal areas of the globe, the problem only can become worse. We must quantify soil erosion more accurately, and we can. Global-scale observations are now possible by using satellite imagery, but as for erosion, even school children can play a local role in quantitative monitoring of their region.

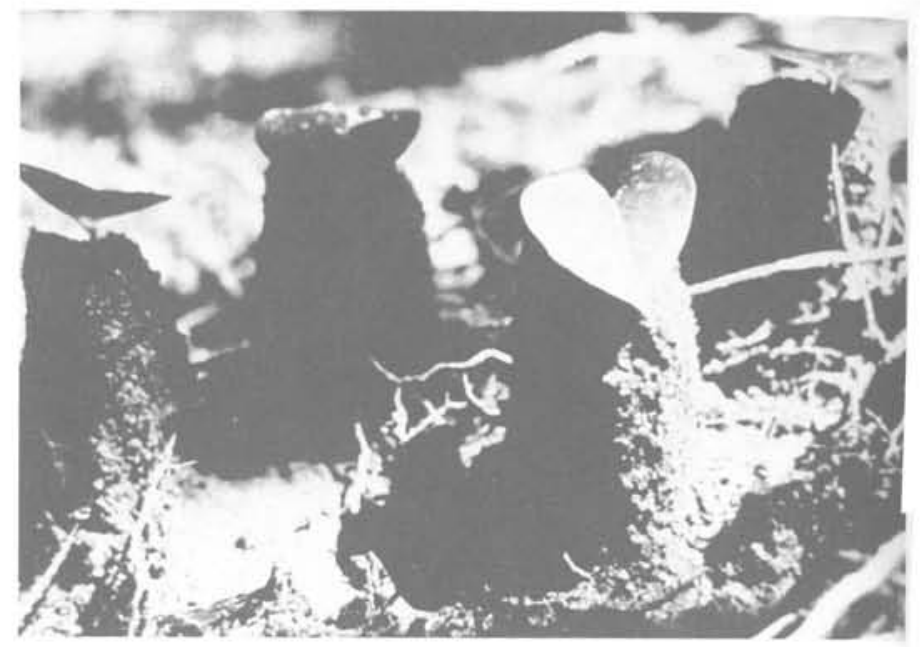

Figure 6. -A picture given to me by a worker in Thailand shows the catastrophic effects of rain-impact erosion. Several centimeters of soil have been lost in a single rainfall.

Most important, erosion can be controlled now with intelligence and with awareness! The systems to control erosion are well known. We have very simple, obvious examples.

- Steep slopes should not be used for intensive agriculture, but should be used for forests (consider Switzerland and Japan). Clearcutting, commonly practiced in Canada even on steep slopes, must be outlawed!

- Even gentle slopes that have fragile soils, heavy rainfall, and rainimpact erosion require continuity of ground cover and no use of herbicides or monoculture agriculture (fig. 6). winds.

The same considerations apply to areas that have frequent high

- In my own home country of New Zealand, where I was born on a farm on the Canterbury Plains, wind erosion in the 1930s was severe. As a result of using new crops that emphasize grass cover and using small fields and prolific planting of belts of trees, the problem now does not exist. In fact, erosion in some of these regions may be lower than before man's arrival when natural fires could sweep across huge areas. I recently visited the Federal Republic of Germany. One can only be impressed by the productivity of their careful agriculture, small fields, crop rotation, organic fertilizers, and trees in profusion.

Perhaps the most spectacular cases of the nonlinear results of soil erosion can be seen in regions of former tropical rain forest (fig. 7). In these areas where evapotranspiration dominates the preman water cycle, the cutting of protective forests on steep topography can lead to catastrophic soil loss within a short time. In fact, reasonable productivity may go to zero productivity within a period of years or even days.

\section{Food, population, and soil}

As we add 90 million humans each year to the Earth, the pressure on food is intense. An obvious conflict between conservation and the urgent needs of billions of people is the result. Ultimately, we must face the limits. Ultimately, we must consider the words of Aldous Huxley in 1948 (see Bedford, 1987, p. 83): "Treat Nature aggressively, with greed and violence and incomprehension: wounded Nature will turn and destroy you. ... . if, presumptuously imagining 
that we can 'conquer' Nature, we continue to live on our planet like a swarm of destructive parasites - we condemn ourselves and our children to misery and deepening squalor and the despair that finds expression in the frenzies of collective violence." And we must consider the words of Pimentel (1987, p. 692): "World resources and technology can support an abundance of humans, e.g. 10-15 billion humans living at or near poverty, or support approximately one billion humans with a relatively high standard of living." Growing evidence of soil-related food problems show that we are approaching our limits and that we are destroying the most fundamental support system of the next generations (fig. 8). We must accept our position in the complex biologic mosaic of a sustainable planet.

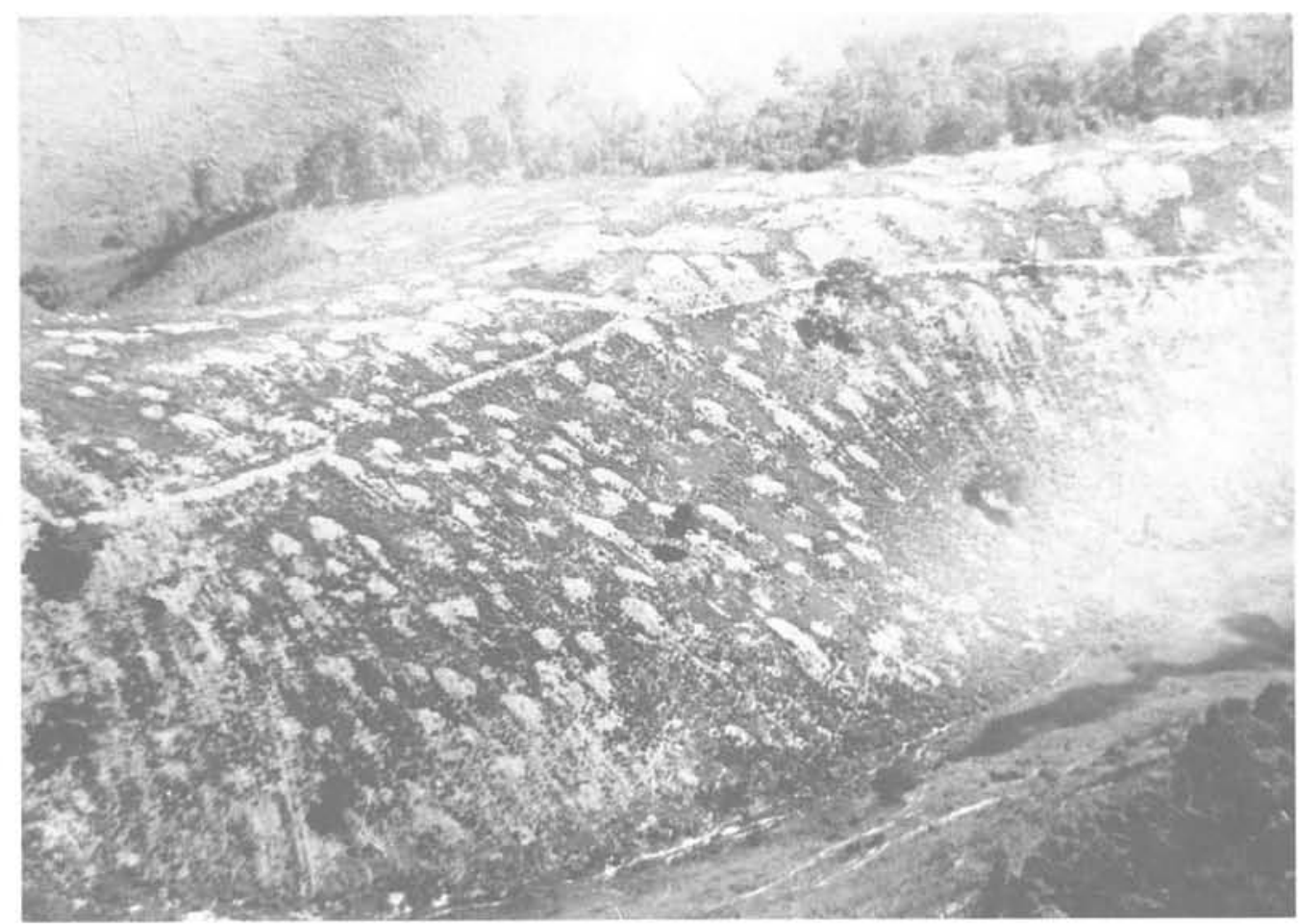

Figure 7.-A new granite outcrop being formed in Rio de Janeiro State, Brazil. The tropical forest has been clearcut for farming, and the soil is now very thin. Soon, bare rock!

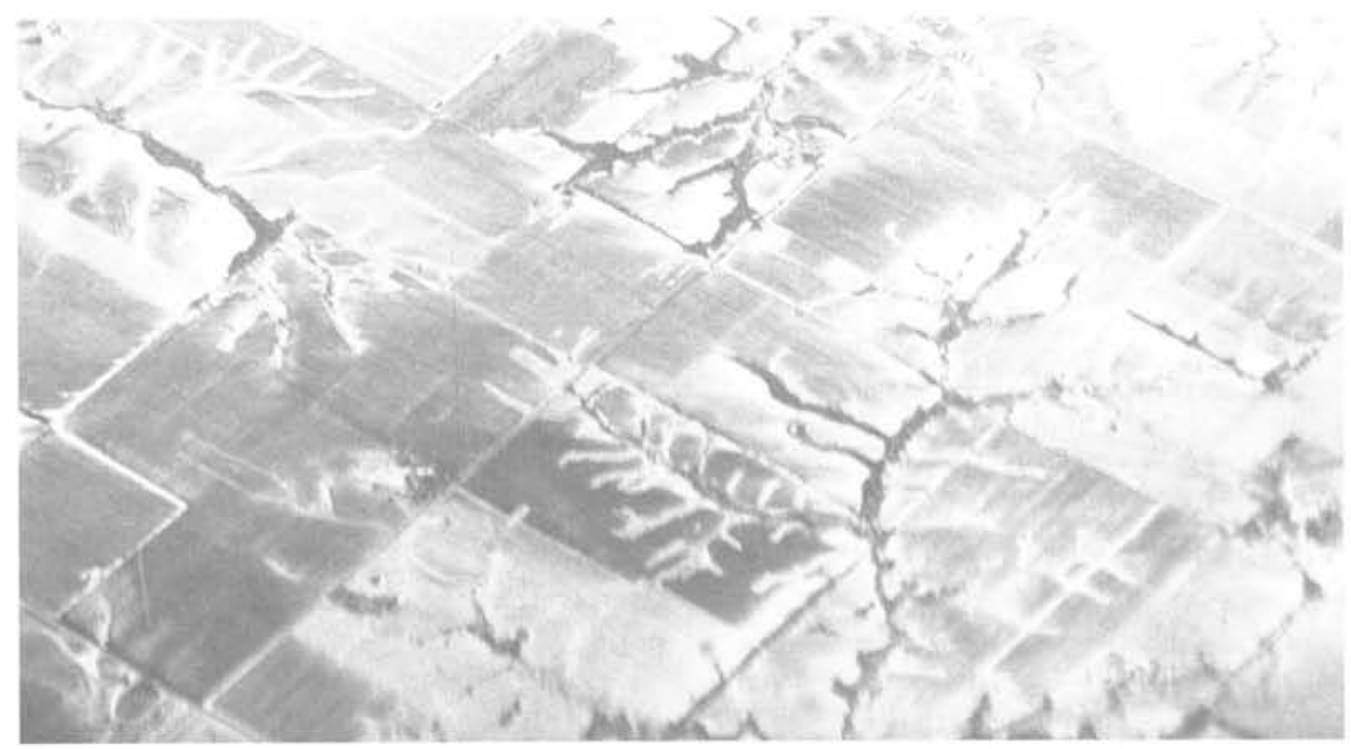

Figure 8.-Land near Des Moines, Iowa, USA, has lost one-half of its topsoil in the past 100 years. 
We need to use new ways to describe soil. This description must focus on sustainable biologic productivity and the carbon-fixing potential for given climatic and geographic situations. The soil map of the future must say: good for careful or intensive farming, good for trees only, don't touch! We know now how to do this, but we rarely do it! Is it too simple? We are moving into the decade for natural disaster reduction. For our future, one of the greatest natural disasters that can be reduced and can be controlled is soil erosion.

\section{Acknowledgments}

I wish to acknowledge the help of Dr. Kazue Tazaki, Dr. Henrietta Mann, and Dr. Grant Ferris, who have worked with me and produced so many wonderful electron microscope pictures of the finegrained materials and bacteria at work in soils.

\section{References}

Bedford, S., 1987. Aldous Huxley, a biography: London, Paladin Grafton Books, v. 2, 378 p.

Berner, E.K., and Berner, R.A., 1987. The global water cycle: Englewood Cliffs, N.J., Prentice-Hall, Inc., 397 p.

Brown, L.R., 1988, The changing world food prospect: The nineties and beyond: Worldwatch Paper $85,58 \mathrm{p}$.

Brown, L.R., and Wolf, E.C., 1984, Soil erosion: Quiet crisis in the world economy: Worldwatch Paper 60, 49 p.

Jacobsen, J.L., 1988, Environmental refugees: A yardstick of habitability: Worldwatch Paper 86, $46 \mathrm{p}$.

Pimentel, D., 1987. Technology and natural resources, in McLaren, D.J., and Skinner, B.J., eds., Resources and world development, Dahlem workshop reports: New York, John Wiley, p. 679-695.

Postel, S., and Heise, L., 1988, Reforesting the Earth: Worldwatch Paper 83, $66 \mathrm{p}$.

Tazaki, K., Fyfe, W.S., and Iwatzaki, M., 1987, Clues to Arctic soil erosion from cryoelectron microscopy of smectite: Nature, v. 333, p. 245-247.

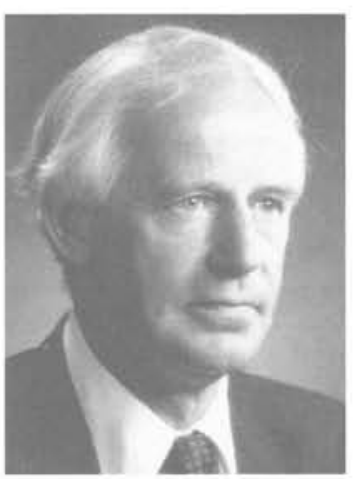

W.S. Fyfe was born on a farm in New Zealand. He studied geology and chemistry at Otago University. He hae taught in New Zealand and at the University of California at Berkeley and Los Angeles, Manchester University (UK), Imperial College (London), and the University of Western Ontario in Canada, where he is presently Dean of Science. Fyfe is a Fellow of the Royal Society of London and Canada. He recently received the Authur Holmes Medal of the European Union of Geosciences. 